\title{
Impact of Social Media on Public leadership: A case-study of Public Officials in Lanzhou, China
}

\author{
Sajjad Haider', Zhu Yanru², Fan Yunxin ${ }^{3}$
}

\begin{abstract}
This study explores the changing leadership role of executives in public sector organizations in Lanzhou city (China) in response to new developments and innovations in organizational and social life. As the internet and technology has transformed the workplaces, so do the managing and leading; and this is one of the crippling challenge for the leadership. Gone are the days of conventional motivational tactics; employees of today are more informed, knowledgeable and smarter than ever before; they can be better enticed through the power of social media. The study involves gleaning empirical data from the mid and upper-mid career officers working in various public sector departments. The findings show that the public officials cannot stay away from the social media and use it frequently at workplaces to connect with their friends and family, and to lesser extent for the organizational purposes, and they adopt the transformational leadership style. The findings of this study are useful to help understand leadership styles adopted by the public sector officials and how the social media impacts their work behavior.
\end{abstract}

Keywords: China, Public leadership, public officials, public sector organization, social media.

Available Online: 12-10-2016

This is an open access article under Creative Commons Attribution 4.0 License, 2016.

1.0

\section{INTRODUCTION}

\section{"Leadership and learning are indispensable to each other". John F. Kennedy}

The world is now moving beyond the globalization and transforming into a knowledge society, knowledge economy and of course knowledge-driven organizations. This shift from agrarian to industrial and from industrial to knowledge society has come up with both opportunities as well challenges. Among many, one of the problems we faced in the transition from an industrial society to a global knowledge economy is the need for a new breed of leaders and a new understanding of leadership (Johannessen, 2013; Miller, 2005). The leaders in both public and private sector need to have a blend of skills (i.e.) the coventional leadership traits like charisitmatic and inspirational personality,

\footnotetext{
${ }^{1}$ Ph.D. Student, School of Management, Lanzhou University, China. Lecturer, Karakoram International University (KIU)

2 Business School, Imperial College London, UK.

3 School of Economics, Georgia Institute of Technology, USA.
} 
good communicator, being visionary are important of course; albeit to be successful in modren era public leaders needs to be tech-savvy and well versed with today's knowledge-driven culture.

With the explosion of the internet, print and electronic media, and dramatic increase in the use of social media; people have unprecedented easy access to information. As a result, people are becoming more and more informed and well connected with each other. Now people's lives are increasingly dependent on these gadgets, tools and technologies. Imagine, for a moment that when Christopher Columbus discovered American in 1678, we were using smartphones and the connected social media-what would have happened? Certainly there would be a big blast in social media. People in every nook and corner of the world would come to know about this discovery. But in fact, in 1678 only few people knew about this big discovery. Columbus would have had few people to celebrate with at that time. Hence, the world today is transformed by the power of technology and social media.

One of the critical challenges faced by public sector organizations in the modern era is to effectively cope with changing needs of the workforce and effectively handle today's many technological challenges. In order to get succeed in today's fast-paced, complex and uncertain time, a leader not only needs to be well versed in conventional administrative and management dynamics, but must also have a broad understanding of the political, economic, social, legal and environmental drivers of change as well the capacity to position their organizations to deal effectively with the many ensuing challenges. The challenge this study addresses is that of rapid technological innovation and its impact on the organizational culture, work processes, communication patterns, and supervisory relationships.

With the advent of new technologies, gadgets, high-tech equipment's and smart devices; human life has dramatically changed. Our daily routines are completely different from those of the past. Today we have easy access to an incredible amount of information. According to McKinsey, China has the biggest internet user base, 513 million people, which is double the 245 million users in the United States and almost equivalent to the combined populations of France, Germany, Italy, Spain, and the United Kingdom (Chiu, Ip, \& Silverman, 2015). Currently the number of social media users in China is 410.5 million, and it is estimated that the number will jump to 473.6 million in 2017 (Statista, 2015). The statistics show that almost a quarter of total population of China is connected online and using some kind of social networking platform. A Boston Consulting Group study found that Chinese Internet users are online for an average of 2.7 hours per day, considerably more than other developing countries and more on par with usage patterns in Japan and the United States (Crampton, 2015).

There is dearth of studies on the impact of social media on public leadership. There are some studies on social media and leadership in context of private sector, nonetheless specifically about the impact of social media on leadership in public sector organizations is scarce. The intended study endeavors to explore how the executives in public sector organizations in Lanzhou use social media for organizational and personal purposes; and how they lead and manage their human resources in contemporary era of smart devices.

Since the research is exploratory, the specific research questions are as follows:

i. What leadership style officials in public sector organizations are adopting to manage their employees and organizations?

ii. To what extend they use the social media to connect with their teams and whether social media can be helpful or hamper their work performance?

This study explores the new leadership role in public sector organizations in the city of Lanzhou. Compared to the western world, leaders of Chinese organizations exhibit distinctly different leadership narratives and styles to achieve results-oriented success. The results of this study will be useful for understanding the subtleties of leadership in China, and guide the practicing public officials in embracing new challenges of leadership; especially related with the use of technology and social media at work. On top of it, the study calls for having a comprehensive policy in organizations to deal with the emerging issues of cyber and social media. 


\subsection{LITERATURE REVIEW}

The study of leadership is always insightful and intriguing because it deals directly with human behavior and emotions. The systematic study of leadership was catalyzed by the industrial revolution and has risen to the level that is among the most researched concepts in behavioral sciences (Gavino, 2013). A wealth of literature is available on almost every aspect of leadership, especially in the private sector, but also to a lesser extent in the public sector.

The theory of New Public Management (Osborne \& Gaebler, 1992) has strengthened the relationship between leadership in the public and private domains, and has resulted in application of termonology from the private sector being used also in the public sector. Examples include transformational, transactional, inspirational, and charistmatic leadership. (Osborne \& Gaebler, 1992; Vermeeren, Kuipers, \& Steijin, 2013).

\section{$2.1 \quad$ LEADERSHIP THEORIES}

In the 1840s, Scottish historian and writer Thomas Carlyle proposed the "Great Man theory", which entailed that history can be largely explained by the impact of "great men", or heroes-highly influential individuals who by virtue of their personal charisma, intelligence, wisdom, or political skill shaped the history of the world-like Napoléon Bonaparte, Eisenhower and Churchill etc. Nonetheless, in 1860 Herbert Spencer (1820 - 1903), an eminent sociologist, came up with the staunch criticism of the Carlyle's theory by asserting that the great men are great because of the situation and circumstances that enabled them to be great leaders (Changing Minds, 2015; Leadership Central, 2015; Wikipedia, 2015). Both Carlyle and Spencer's approaches to leadership remained the center of leadership discourse throughout the 19th-century and early 2oth century. The Great man theory also suggests that the leaders are born, not made, which opened a never ending debate on whether leaders are really born or can be made. Behavioural psychologists negate the notion asserting that the leadership skills can come through education, training, experience, surroundings and so on.

Kurt Lewin (1890-1947) identified three leadership styles which still dominate the locus of leadership style (i.e.) Autocratic, participatory or democratice and laissez-faire leadership (Lewin, Lippit \& White, 1939). The Autocractic or Authoritarian is a leader who uses coercive force or authority to achieve the desired goals. This leadership sytle is generally considered to be undesirable in a civilized world. The second style is a participatory or democratic style of leadership. As the name suggests, the leader in this style involves his/her team, employees or folllowers in decision making processes to build consensus. These decision making processes, by necessity, sometimes take significant time to get everyone on board and getting everyone on the same page. The third style Lewin describes is the Laissez-faire stype of leadership. This is also called as free-reign or easy-going as these kind of leaders are generally lenient, flexible and carefree about the task, goal, or purpose at hand.

In 1960s, Blake and Mouton (1964) proposed their seminal leadership and managerial grid that measures leadership styles in two dimensions-concern for results and task, and concern for people. It includes five key managerial and leaderhsip styles: impoverished, country club, middle of the road, authoritarian, and team.

The situational leadership style proposed by Hersey and Blanchard $(1969,1977,1999)$ asserts that leaders should adapt a leadership style based on the development style (or level and ability) of followers and how ready and willing the follower is to perform required tasks as well as keep in view the situation at hand. This leadership style got much popularity because of its practicability in real situations. Many leaders adopt this style to tackle the complexe issues and uncertain situations (Pawel, 2013).

In 1978, James MacGregor Burns first introduced the concept of transformational leadership, which later become the basis of this current leadership research. Burns (1978) suggests that transformational 
leadership is a process in which leaders and followers help each other to advance to a higher level of morale and motivation.

Transformational theory is an enlighted leadership theory which seeks to make tomorrow better, it endeavors to instill vision and pupose in employees. It is based on the philosophy of motivating and galvanizing employees and followers to get the desired results. As the name suggests, transactional theory largely deals with the transactional, generic, and administrative kinds of activities a leader does. Burns transformational theory was later further refined and expaned by Bass and Avolio based on the impact that it has on followers. He emphasized that the transformational leaders need to gain trust, respect and followership from the followers (Bass \& Avolio, 1997; 2000; Burns, 1978; Zigurs, 2002).

\subsection{SOCIAL MEDIA}

The importance of social networking gained popularity in the 1980s when managers who had a wide social cricle were considered to be effective managers (Pawel, 2013). The notion that people and relationship skills are critical to leadership and management extends into networking through social media. While conventional face-to-face interaction and meeting with people is still important, networking through social media is cost effective and can help connect many people at the same time (Pawel, 2013; Tredgold, 2014; Zaccaro \& Bader, 2002).

The power of social media is sufficiently strong and overarching that none can escape from it (Tredgold, 2014). A leader or a manager who is not familiar with social media may considered a conventional or orthodox person. Indeed, one of the factors of success of today's leaders is their ability to effectively use social media and social networking for their personal and organizational benefits. It's convenient, cost-effective, and less time consuming because there is no need of direct interaction with other members (Pawel, 2013). Social media can also be used to connect with the employees and teams, provide them timely support, input and feedback. It's also becoming a popular tool to galvanize and motivate employees; as employees would be delighted to receive appreciation from the boss through a post on their social media page (Tredgold, 2014; Zaccaro \& Bader, 2002).

Given the robust advancement in information and communication technology, the conventional leadership traits of charismatic, inspirational, authentic leaders have been transformed into a new kind of leader that can be called an e-leader (Avolio \& Kahai, 2003; Duarte \& Snyder, 2006; Zaccaro \& Bader, 2002). Now the physical presence of a leader in front of the followers, employees, and teams is not necessary; the new technology can handle it better. Sitting thousands of miles away, a leader can address his/her employees and share their future plans of action (Avolio \& Kahai, 2003; Korzynski, 2013; Zigurs, 2002). Leaders and managers who can master social media skills will be able to significantly increase their influence (Tredgold, 2014) and significantly benefit their personal as well as professional life (Duarte \& Snyder, 2006).

Increasingly now, executives (both public and private) are connecting with their employees and teams through virtual plateforms; saving cost, time and doing it in a convenient way. Given the fast-paced developments, challenges, and the size of tasks at hand, leaders find they can't afford to spent so much time in conventional boardroom style meetings; they find success in managing entire projects from a distance and interact with the followers or team members using information technology (Avolio \& Kahai, 2003). This is a new way of doing work and it differs from the past in many ways. Hence a new barometer of leadership effectiveness has emerged which recognizes those who frequently use social media for organizational and personal networking.

Social media has provided open access for citizens and customers of a product to share their grievances, feedback, or opinion about the quality of civic services or the products instantly. Not only they can lodge complaints, but they can also share best practices and suggestions through online platforms, blogs, virtual communities etc. (Tredgold, 2014). In U.S., from the mid-2000s onwards there 
was an increase in the number of public sector organizations using one or more social media platforms to engage the public .

Duarte and Snyder emphasized that contemporary leaders need to learn new things and be able to use new technology for the benefit of the organization (2001). McKinsey \& Company has identified six social media skill sets every leader needs to personify: (a) leader as producer, creating and compiling content; (b) leader as distributor, leveraging dynamics of dissemination; (c) leader as a recipient, managing communication overflow; (d) leader as adviser and orchestrator, driving strategic socialmedia utilization; (e) leader as architect, creating an enabling organizational infrastructure; and (f) leader as analyst, staying ahead of the curve (McKinsey \& Company, 2015).

\subsection{THEORETICAL FRAMEWORK}

The modern era is characterized by a proliferation of gadgets, tools and technologically innovative equipment. Everyone is affected both directly and indirectly, and public leaders are no exception. This technology revolution has also affected leading and managing organizations, both public and private. Private sector organizations generally keep abreast of technological advancements in order to gain an edge in fierce competition. On the other hand, public organizations, having strong hierarchical control, centralized decision-making, and much red-tape inhibit adaption of new technology. Although public organizations are comparatively slow to adopt new trends, they nevertheless do accrue some benefits of new technology in their own way.

Among the host of challenges faced by organizations today, one of the most critical is to develop a new breed of leaders (Johannessen \& Skalsvik, 2013) to cope up with the emerging and complex issues. Leaders need new sets of skills and competencies that were not required twenty or twenty-five years ago including being skillful in technology, social media, and social networking. Leaders now require not only the conventional traits and qualities of leadership such as charisma, inspirational \& motivational skills, strategic vision, but also need technological expertise and the ability to use social media for carrying out the organizational tasks in an efficient and effective manner.

Among the variety of available instruments to assess leadership behaviors, we have chosen Bass and Avolio's (1994, 2000 and 2004) multifactor leadership questionnaire (MLQ - also known as MLQ 5X). The questionnaire measures three aspects of leadership style: transformational, transactional, and passive/avoidant.

For our intended study, we employ the research model shown below in Figure 1 to measure results:

Figure 1: Research model
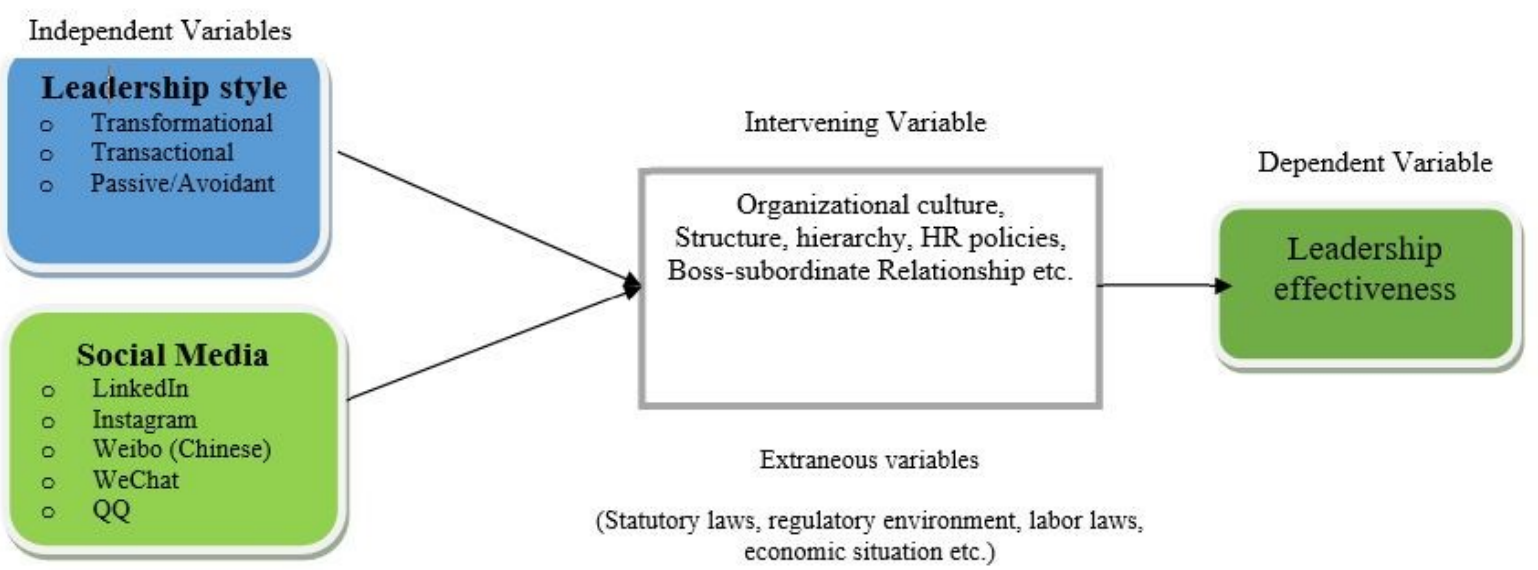
The model illustrates that the public leadership behavior is directly and indirectly affected by the extend to a leader use social media for carrying out day-to-day organizational tasks such as conducting meetings, project planning, execution, use of social media which all adds up to leadership effectiveness. The model shows that the leadership style of public leaders and the use of social media are independent variables. These independent variables combine together with the internal and external elements (extraneous variables and moderator) to influence leadership effectiveness.

The theoretical model tests the notion that in order to succeed in the modern era, public officials not only need to have an appropriate leadership style, but also need to be social media savvy. The underlying reason is that today's workforce is well informed and wants to stay connected with social media. The model illustrates that public leadership behavior is directly and indirectly affected by the extent to which a public official use social media for carrying out day-to-day organizational tasks such as conducting meetings, project planning, execution, and the use of social media. All this adds up to leadership effectiveness. In a nutshell, the study revolves around two important elements (a) the leadership style of public leader and (b) the ability of the leader to effectively use social media to carry out organizational tasks.

\subsection{HYPOTHESES}

$\mathbf{H}_{1}$. Public sector officials in Lanzhou adopt a "transformational leadership style" to manage their employees and organizations.

$\mathbf{H}_{\mathbf{2}}$. There is positive relationship between the transformational leadership style and the leadership effectiveness.

H3: Public officials in Lanzhou are "passive/avoidant"

H4: Public officials in Lanzhou are social media savvy and they use it for various purposes (i.e. social, organizational and personal).

H5: $\quad$ Excessive use of social media in public Lanzhou offices hampers work performance.

\subsection{DATA AND METHODOLOGY}

The study is qualitative exploratory research and the methodology employed is conduct of a survey. The research tool is a questionnaire. Empirical data is collected from the government officials working in Lanzhou city, so the unit of analysis is individuals.

As a pilot study, the research tool has been pre-tested on a small sample of full time MPA and MPA Executive students who hold positions in various government departments in Lanzhou city. Based on the pilot study, some minor modifications have been made in the research tools and overall methodology.

Empirical data has been collected through the questionnaire which consists of 19 close-ended questions, excluding the demographic and personal information. The questionnaire uses a 5-point Likert scale scored from 1 as 'strongly disagree/never true' to 5 as 'strongly agree/always true'. The research tool has been adopted from the widely used leadership questionnaire known as a 'multi-factor leadership questionnaire (MLQ 5X) proposed by Bass \& Avolio (1994, 2000, and 2004). The MLQ model measures the leadership on three important aspects: transformational, transactional and passive / avoidant leadership styles. No existing instruments measure use of social media so we designed one for this study. The questionnaire is bi-lingual in English and Chinese; to make it convenient for the respondents to better to understand and respond the questions. It has been designed mindful of the cultural, socio-political situation, and the unique hierarchical structure of the public sector organizations in China.

A stratified random sampling method has been employed to ensure a representative sample from the target population (governmental officials working in various departments in Lanzhou city). A total of 
300 questionnaires were distributed, from which two 230 were returned yielding a response rate of $76.66 \%$. Twenty-two questionnaires were incomplete, so they were rejected. There were 208 completely filled out questionnaires giving a sample size of 208. The data has been analyzed using the Statistical Package for Social Sciences (SPSS).

\subsection{RESULTS AND DISCUSSION}

\subsection{RESULTS}

\begin{tabular}{|c|c|c|c|}
\hline \multicolumn{4}{|c|}{ Table 1: Cronbach's Alpha } \\
\hline \multicolumn{4}{|c|}{ Item Statistics } \\
\hline & Mean & iation & $\mathrm{N}$ \\
\hline Trnf-1 & 4.44 & .726 & 208 \\
\hline Trnf-2 & 3.98 & .633 & 208 \\
\hline Trnf-3 & 4.38 & .825 & 208 \\
\hline Trnf-4 & 4.17 & .916 & 208 \\
\hline Trnf-5 & 3.88 & .857 & 208 \\
\hline Trnsc-6 & $4 \cdot 35$ & .820 & 208 \\
\hline Trnsc-7 & 2.46 & .735 & 208 \\
\hline PA-8 & 1.59 & .607 & 208 \\
\hline PA-9 & 1.89 & .628 & 208 \\
\hline
\end{tabular}

\subsubsection{LEADERSHIP}

With the average mean of 4.06 and average median of 4.46, we can construe that the leaders fairly often, or even frequently, go beyond self-interest for the good of the team, and they adopt the transformational leadership style in managing their employees and carrying out the organizational tasks. This is one of the vital component of transformational leaders' traits. Well educated, dynamic and optimistic; the young professionals in public sector organizations aspire to be the transformational leaders in China. Secondly, the results show that they are concerned about the moral and ethical consequences of the decisions they made. We can infer from this that their decision-making process is systematic and logical, and they account themselves for the decisions they made. They are optimistic about the future, and they have a high spirit to continue rising high. The results also imply that the leaders are frequently reflecting upon themselves and the decisions they made; they fairly and objectively evaluate their decisions and remain cautious and extra-careful about their future decisions. They learn from their mistakes, and refine and improve their decision- making. This reflects one of a critical trait of a transformational leader to continuously learn and improve. This also shows that they want themselves accountable for their decisions and actions.

Moreover, the results also exhibit that the young official and leaders are not "Passive/ Avoidant"; rather they are active and proactive in managing the tasks. Hence, we can infer that the majority of leaders in public sector organizations in Lanzhou won't wait till things go wrong, rather they take proactive or preemptive actions in avoiding things to go wrong. A high score on this question could have indicated that the leaders are passive and avoid taking proper steps and actions; this could show lackluster attitude that sometimes results in disastrous consequences. Nevertheless, the results are positive in this case and portray an optimistic picture about the leaders.

\subsubsection{SOCIAL MEDIA}

The data gathered illustrates that the majority of the people "agree" (68.8\%) that they use social media for various purposes. $26.4 \%$ strongly agree to connect with the social media; while a fraction of the 
respondents (only $4.8 \%$ ) disagreed that they use any form of social media. This shows the widespread popularity of the social media among officials in Lanzhou city and proves that they stay connected with their teams, bosses, friends and family.

\section{Graph 1}

I often use Social Media

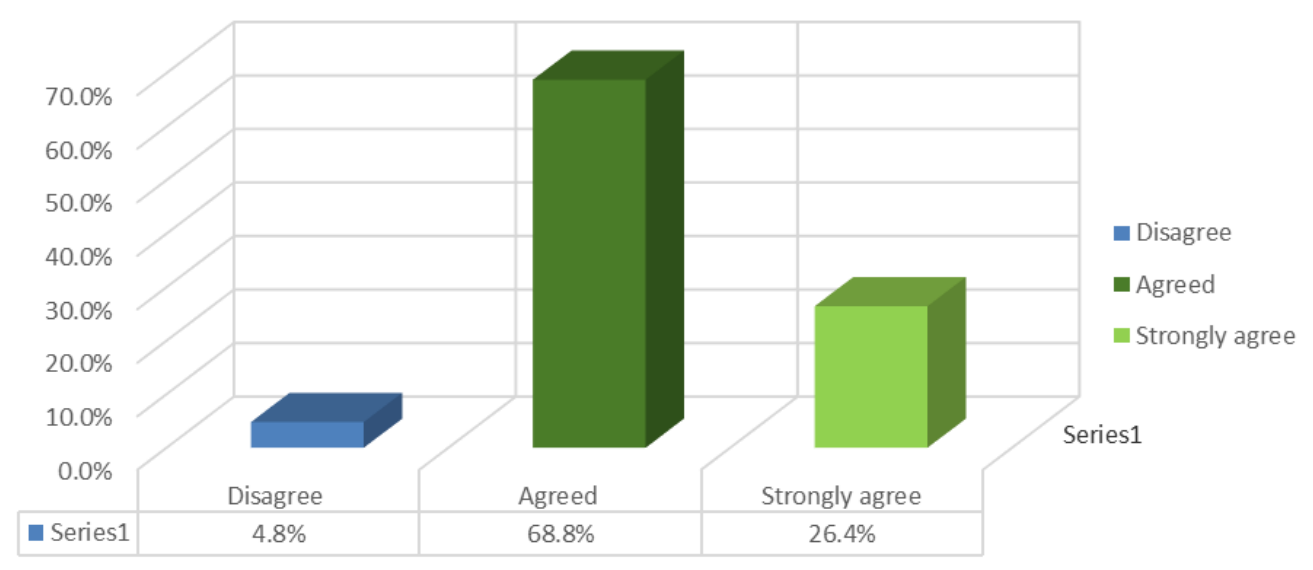

The responses to the question of "how social media has affected your life", $41 \%$ of responded believe that it made life both easy and difficult, $11 \%$ say it made life quite difficult and busy; whereas $23 \%$ responded in favor of social media and said it made life comfortable and convenient, and $25 \%$ are of the opinion that it made access to information possible.

The question about whether or not "the excessive use of Social Media in offices hampers the work performance", the responses are somehow mixed. $11 \%$ respondents strongly agree, and $38 \%$ agree that continuous use of social media in workplaces hampers the work performance; whereas $28 \%$ are neutral and they are not sure about the disruption in work performance due to social media. However, there are some people who tend to disagree (22\%) with this notion.

\section{Graph 2}

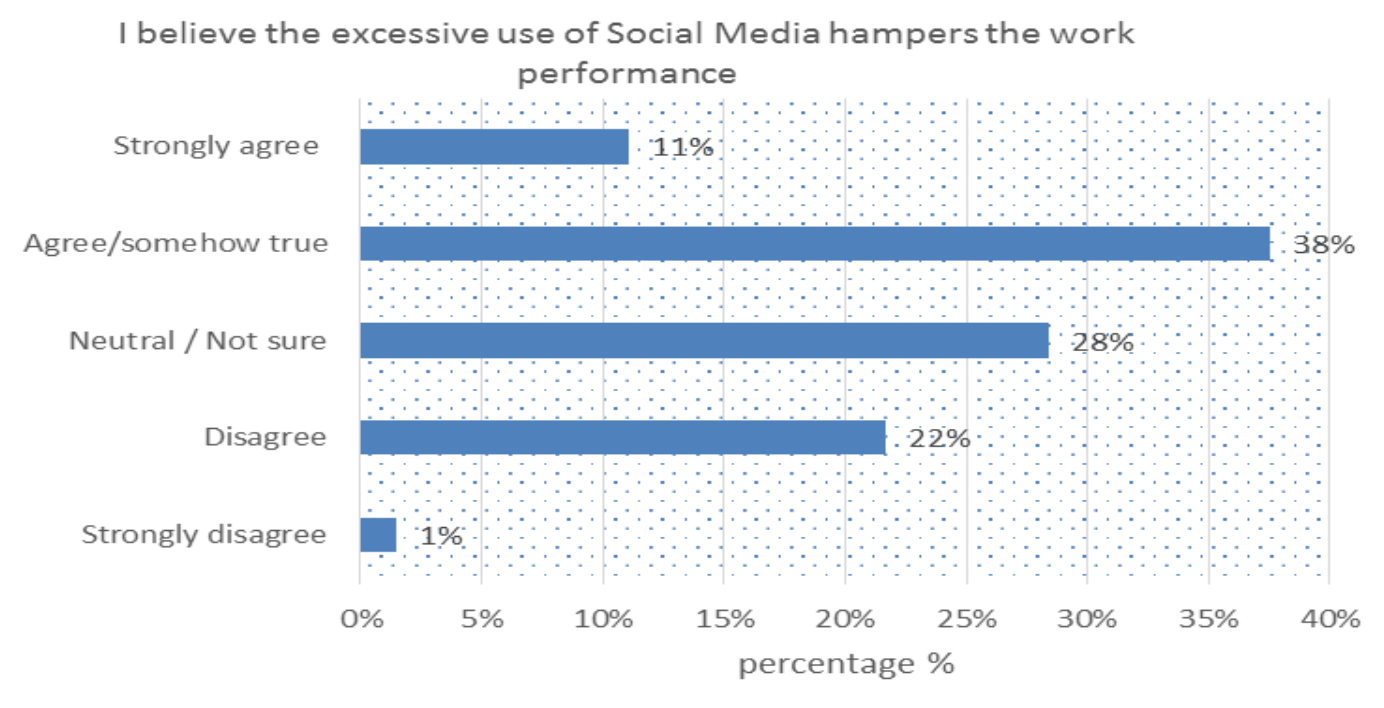


On question of type of social media use, the majority of responded use WeChat (69\%) and QQ (63\%) in Lanzhou city. Weibo is another social media network people often logged-in to (21\%). Linkedln, the widely used professional networking site in western countries, seems less popular in a relatively smaller city of China, nonetheless; $11 \%$ responded intermittently use Linkedln to connect with professionals of their field.

Social media is used for various purposes and broadly we categorized into three (i.e.) social, organizational and personal purposes. Accordingly, Linkedln is primarily used for professional and personal networking (47 responses). Whereas WeChat and QQ is almost equally used for personal (189, $185)$ as well as social networking purposes $(193,191)$. To lesser extent $(45,55)$, both networks are also used for organizational purposes such as disseminating the information, news to public and connecting with citizens to get their feedback. Other social media Weibo is mostly used for social networking purposes (103).

The bar chart below shows the usage of social media for various purposes. Most responses were in favor of connecting with friends and family ( $87 \%$ and $85 \%$ respectively). A bunch of responses shows that social media is widely used for disseminating information and public relations (71\%) in Lanzhou city. Other significant usage in offices are connecting with team and employees (63\%), getting feedback from clients (59\%) and connecting with the top management (56\%). To relatively lesser extent, it is also used for other purposes like e-government (37\%) and improving the work processes and bringing efficiency (20\%).

The data shows that social media is quite popular in amongst the officials, especially the middle level managers, and they are well versed in using it for various purposes.

\section{Graph 3}

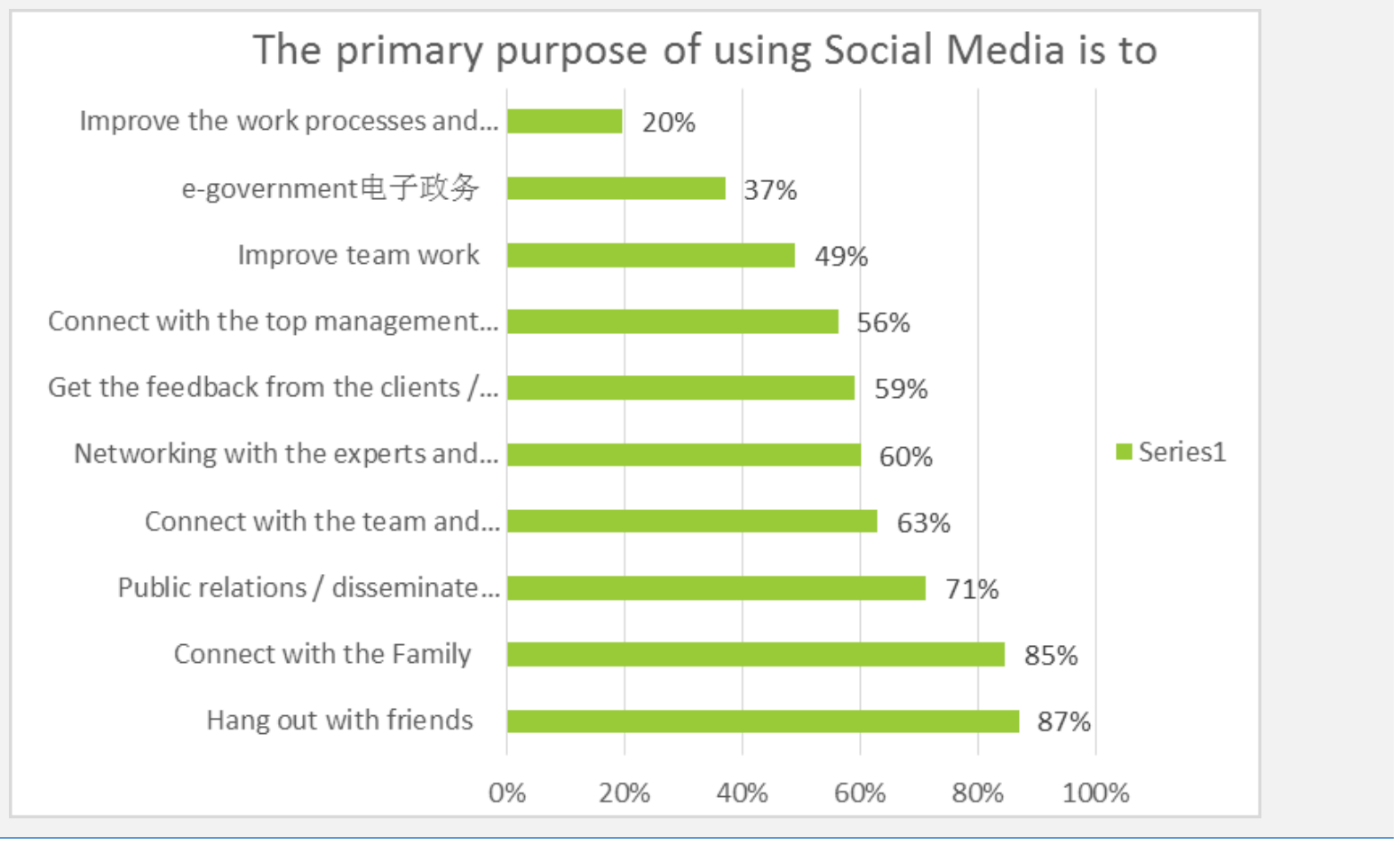

The data gathered also reflected that staggering $4 \%$ say they have a comprehensive policy of social media covering virtually everything, nonetheless; $20 \%$ responses shows that the organizations have a policy regarding social media but not a comprehensive one. $5 \%$ are of the opinion that the policy making is under consideration, and 30\% negate there exists any policy in their organizations. Bulk of people (40\%) don't know about the existence of any policy for social media use in their organizations. 


\section{Graph 4}

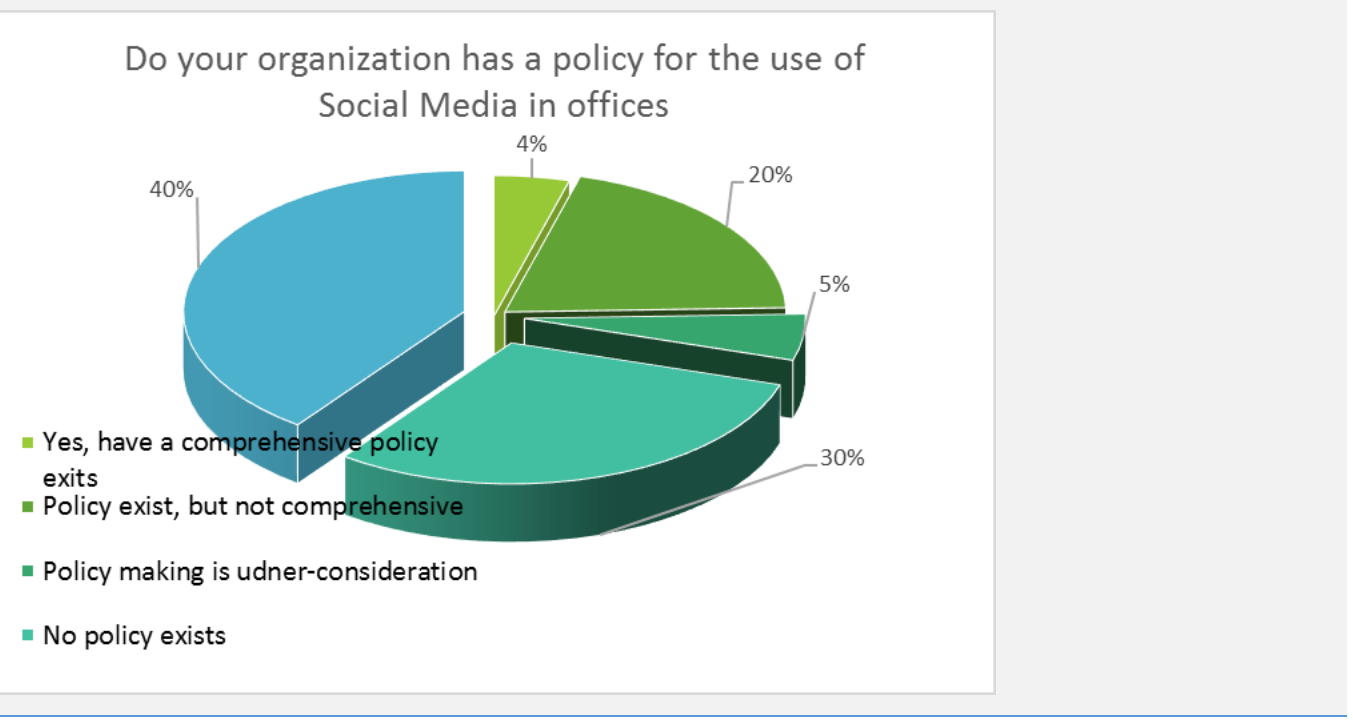

\subsection{DISCUSSION}

While contemplating leadership styles, an obvious question comes into mind: Is there one best way or ideal leadership style? While scholars respond to this question in various ways in different contexts, Burns (1978) asserts that there is no one best way of leadership and suggests that effective leaders use a combination of different styles that he calls a situational leadership style.

No matter how big or small, public or private, for-profit or not-for-profit; every organization is steered by a leader. The success or failure of the organization is largely dependent on its leadership. Those organizations fortunate enough to have wise, visionary, and forward-looking leaders have potential to soar far higher than those who do not. Successful leaders of today have a combination of transformational leadership traits as well as being social media savvy. They can use social media and technology effectively for personal as well as organizational excellence.

There is little research on leadership behavior and online social networking in the Chinese context. However, results drawn from other countries suggest that leaders tend to connect well with diverse kinds of people to leverage both organizational and personal benefits (Pawel, 2013). Undeniably, social media has emerged as a powerful force which shapes our thinking. Therefore, our research supports previous research being conducted in other countries and organizational settings.

While there are significant benefits for employees being social media savvy, there are also drawbacks to excessive use of social media in workplaces, especially revolving around sharing personal posts, comments, and counter-comments in a never-ending chain of communication which hampers the work performance of employees.

Undoubtedly, social media has reshaped social and organizational culure and enabled both private and public sector organziations to directly connect with the citizens (Miller, 2005). However, this has posed some risk too in that some unscrupulous people may use fake identifications to deceive people and perpetrate hoaxes in the name of organizations. These cause loss of confidentiality and intrusion in personal life and privacy issues; but more importantly, social media sites are more prone to hacking. Organizations therefore need to be extra vigilent and careful about such fraudulent acts. Even so, they shouldn't give up using the most powerful tool of the time to connect with their customers, clients, and citizens.

Public sector websites are a useful tool to provide relevant, timely and accurate information to the public, which otherwise would be provided by traditional means which require a lot time and effort. In 
addition, traditional websites are typically not updated in a timely fashion. Also, they are usually taken for granted and not seriously and carefully managed. Another pitfall assocated with websites of public sector organizations is that they are frequently static websites with very few being interactive to provide live information. This trend has, however, been supplemented only recently by the use of social media, which is, by definition, interactive (Dubois \& Bray, 2015).

Overall the result presents some key findings. First, the empirical data shows that may officials in public sector organizations in Lanzhou city prefer to use transformational leadership styles in carrying out their tasks. Some opt for a transactional style because it is hard to depart from the status quo. The young and middle level officials, being well educated and from the good institutions tend to opt for transformational leadership style. Others use a blend of both transformational and transactional style of leadership, what Hersey and Blanchard $(1969,1977,1999)$ call a situational leadership style; carefully switching to both ends and adopting an approach suited to the situation at hand. Second, the study results show that the majority of public officials in Lanzhou are well versed in the use social media and they use it for various purposes including connecting with family and friends, however; its use in organizational purposes is still scant, and needs to to be improved in order to provide timely information and better services to the citizens. Thrid, furthermore, the results also indicate that online social networking platforms are gaining more and more popularity in China. They are primarily conceived of as serving only social and personal networking purposes. They are, however, being used to some extent for organizational purposes (such as connecting with teams, employees and boss, and dissemination of information). Fourth, public leaders, like leaders in the private sector, play a significant role. The impact of the decisions made by public leaders are often more far reaching and have a more prominent direct and indirect impact on the lives of people than decisions made in private sector. Since the public sector is one of the largest employers in most countries, including China, and since the role of public sector organizations is inescapable from people's lives; a study to get to know the leadership dynamics in public sector organization might provide useful insight. Fifth,the public officials in Lanzhou city adopt the transformational leadership style in managing and leading their people and organizations. There is positive relationship between the transformational role of leadership and leadership effectiveness. Finally, some leaders still believe in transactional role of leadership, these are mostly older people who are unwilling to change the status quo. Social media is a popular platform to connect with friends \& family as well as co-workers and teams. Nevertheless, its use for organizational purposes still needs to be enhanced.

\subsection{CONCLUSION}

Public leaders in the contemporary world need to have an array of skill sets, ranging from transactional skills to transformational as well as being social media savvy. Being only inspirational and having a charismatic personality is not sufficient in today's world. Technology has revolutionized everything we do including in how we exercise leadership. E-leaders and managers are well versed in emerging technologies and use it for appropriately personal as well as organizational purposes (Avolio, 2003). Moreover, employees now feel more comfortable connecting with their bosses through social media tools, rather than through personal meetings scheduled by appointment in a bureaucratic way.

The world witnessed a surge in social media use from mid-2010 and in China from 2008 forward. Now there is no escape, but rather a need to make a strategy to use it. The good news is that officials in Lanzhou are well aware and well versed in the use the social media for personal, social, and to some extent for organizational purposes. However, its use needs to be further expanded to enable general masses to get their desired information about government activities from social media. As the result of social media's user friendliness, people can easily acquaint themselves with the work of government without any extra effort. With the information boom, a new type of relationship is emerging, more powerful, flexible and effective-the social media relationship. Hence, the social media is a powerful tool for people to stay connected and stay informed. 
Despite its benefits, there are some risks associated with the use of social media if not dealt with carefully including identity theft, hacking, privacy issues, and even the potential incitement of racism and violence.

There is great potential for future research in this area because it has not been explored in a Chinese context and because social media is taking an increasing place in our professional, social, and personal lives. Finally, successful leaders in the ever changing world need to be social media savvy and conversant in the use of prevelent technologies.

\section{ACKNOWLEDGEMENT}

The authors sincere thank Dr Gary Larsen, adjunct professor of Public Administration at the Portland State University and Lanzhou University, China, for his invaluable insights and guidance in completion of this research work. We also thank Dr Wang Xuejun, associate professor, School of Management Lanzhou University for his continuous guidance and input.

\section{REFERENCES}

Avolio, B. J., \& Kahai, S. S. (2003). Adding "E" to E-Leadership: How it may impact your leadership. Organizational Dynamics, 31(4), 325-338.

Bass, B. M. \& Avolio, B. J. (1997). Full range leadership development: Manual for multifactor leadership questionnaire. California: Mind Gorden, Inc.

Bass, B. M. \& Avolio, B. J. (2000). MLQ Multifactor Leadership Questionnaire sample set: Technical report, leaders form, rater form, and scoring key for MLQ From 5x-Short. (2. ed., Ed.) Redwood City, CA: Mind Garden.

Blak, R. R., \& Mounton, J. S. (1964). The Managerial Grid. Gulf: Houston, TX. .

Burns, J. M. (1978). Leadership. New York: Haper and Row.

Changing Minds. (2015, August 4). Retrieved from Changing Minds: http://changingminds.org/disciplines/leadership/theories/great_man_theory.htm

Chiu, C., Ip, C., \& Silverman, A. (2015, August 30). McKinsey Quarterly. Retrieved from McKinsey \& Company:

http://www.mckinsey.com/insights/marketing_sales/understanding_social_media_in_china

Crampton, T. (2015, August 24). Social media in China: The same, but different. Retrieved from China Business Review: http://www.chinabusinessreview.com/social-media-in-china-the-same-butdifferent/

Dillman, D. A., Smyth, J. D., \& Christian, L. M. (2014). Internet, Phone, Mail, and Mixed-Mode Surveys: The Tailored Design Method (4th ed. ed.). Wiley.

Duarte, D.L. and Snyder, N.T. (2006). Mastering virtual teams: Strategies, tools, and techniques that succeed (3rd ed.). San Francisco, CA: Wiley.

Dubois, Corina \& Bray, A. D. (2015, August 24). Improving how social media informs leadership and public initiatives. Retrieved from Digital Gov.: http://www.digitalgov.gov/2015/03/18/improvinghow-social-media-informs-leadership-and-public-initiatives/

Gavino, J. C., \& Portugal, E. J. (2013). Leadership framework: A preliminary qualitative research using the critical incident method. World Review of Business Research, 3(4), 40-52.

Johannessen, J. A., \& Kålsvik, H. (2013). The systemic leaders: new leaders in the global economy. Emerald Insight, 42(1), 13 - 34 .

Johannessen, J-A., \& Skålsvik, H. (2013). The systemic leaders: new leaders in the global economy. Emarald Insights, 42, 13 - 34.

Korzynski, P. (2013). Online social networks and leadership: Implications of a new online working environment for leadership. International Journal of Manpower, 34(8), 975 - 994.

Kumar, R. (2005). Research Methodology-A step by step guide. SAGE Publications.

Leadership Central. (2015, August 4). Retrieved from Leadership Central: http://www.leadershipcentral.com/great-man-theory.html\#axzz3hocL7JjG 
Lewin, K., Lippit, R., \& White, R.K. (1939). Patterns of aggressive behavior in experimentally created social climates. Journal of Social Psychology, 271-301.

McKinsey \& Company Insights and Publications. (2015, August 5). Retrieved from McKinsey \& Company: http://www.mckinsey.com/insights/high_tech_telecoms_internet/six_socialmedia_skills_every_leader_needs

Miller, M. (2005). The digital dynamic: how communications media shape our world. The Futurist, 39(3), 31-36.

Pawel, K. (2013). Online social networks and leadership. International Journal of Manpower, 34(8), 975 994.

Statista. (2015, October 1). Retrieved from Statista: http://www.statista.com/statistics/277586/numberof-social-network-users-in-china/

Tredgold, G. P. (2014). Are you connected? Leadership in the era of social media. Development and Learning in, 28(6), 9 - 11.

Vermeeren, B., Kuipers, B., \& Steijin B. (2013). Does leadeship style make a difference? Linking HRM, job satisfaction and organizational performance. Review of Public Personnel Administration, 34(2), 174-195. doi:10.1177/0734371X13510853

Wikipedia. (2015, August 4). Retrieved from Great Man theory: https://en.wikipedia.org/wiki/Great_Man_theory

Zaccaro, S.J. \& Bader, P. (2002). E-leadership and the challenges of leading E-teams: minimizing the bad and maximizing the good. Organizational Dynamics, 31(4), 339-351.

Zigurs, I. (2002). Leadership in virtual teams: oxymoron or opportunity? Organizational Dynamics, 31(4), 339-351. 